\title{
Analysis of Dynamic Damage-Induced Porosity Changes of Granites in Leaching Mining Technique Based on SHPB Test
}

\author{
Yichen Miao $\mathbb{D}^{1,2}$ Changwu Liu $\mathbb{D}^{2,3}$ Zhiliang He, ${ }^{1,2,4}$ Yuanjun $\mathrm{Ma}^{2,3}$ Haikuan $\mathrm{Wu},{ }^{2,3}$ \\ and Ding Wang ${ }^{5}$ \\ ${ }^{1}$ Institute of Disaster Management and Reconstruction, Sichuan University-The Hong Kong Polytechnic University, Chengdu, China \\ ${ }^{2}$ State Key Laboratory of Hydraulics and Mountain River Engineering, Sichuan University, Chengdu, China \\ ${ }^{3}$ College of Water Resource and Hydropower, Sichuan University, Chengdu, China \\ ${ }^{4}$ School of Environment and Resource, Southwest University of Science \& Technology, Mianyang, China \\ ${ }^{5}$ School of Civil Engineering and Architecture, Southwest University of Science \& Technology, Mianyang, China
}

Correspondence should be addressed to Changwu Liu; liuchangwu@scu.edu.cn

Received 16 July 2020; Revised 25 July 2020; Accepted 27 August 2020; Published 9 September 2020

Academic Editor: Stefan Iglauer

Copyright (C) 2020 Yichen Miao et al. This is an open access article distributed under the Creative Commons Attribution License, which permits unrestricted use, distribution, and reproduction in any medium, provided the original work is properly cited.

\begin{abstract}
In situ leaching was a very important technical approach in ion-adsorption rare earth mining, because it can effectively avoid the geological hazards, protect the environment, and reduce the mining costs. The critical issue of this mining technique was to increase the permeability of ion-adsorption rare earth deposits. Due to the close relationship between the permeability and the porosity, in this paper, several experiments were conducted to find the dynamic characteristics of the granite deposit and the relationship between the dynamic characteristics and the porosity. Moreover, the SHPB test system was equipped to conduct the dynamic test, and the ultrasonic wave detector with high precision was employed to obtain the damage factor of granites. The test results showed that the failure mode under dynamic load and static load was close, and they both had splitting failure. Besides, when cyclic dynamic loading velocity was between $5.8 \mathrm{~m} / \mathrm{s}$ and $8.4 \mathrm{~m} / \mathrm{s}$, the specimen was not a failure, but it caused the damage and changed the porosity. And the dynamic thresholds of failure stress and damage stress were found. Finally, a linear relationship between the porosity and the damage factor was found, which would help to analyze and predict the change of porosity under different dynamic loading velocities.
\end{abstract}

\section{Introduction}

The rare earth elements (REE) are valuable mineral resources, being widely used in advanced electronics, lighting, power generation, and military application. The rare earth elements were first discovered at the end of the 18th century in Sweden $[1,2]$. Until now, China's rare earth reserves are 18 million tonnes, accounting for $23 \%$ of global reserves, which dominated all aspects of supply chains of rare earth minerals in the international markets [3-5]. Chinese and rest-of-world mine production of rare earths is shown in Figure 1.
In 1970, ion-adsorption rare earth deposits were first discovered in Ganzhou, China. These deposits were formed by chemical weathering decomposition and dissolution of granites, which contained relatively high abundance of rare earth elements [7]. Ion-adsorption rare earth reserves only accounted for $2.9 \%$ of the total rare earth reserves in China, and they were sparsely distributed throughout seven adjacent provinces of southern China, which were rarely found anywhere else in the world $[8,9]$. Recently, in situ leach mining was wildly used in ion-absorption rare earth mining, because of lower cost and more environmental protection. Extraction of rare earths from ore deposits was 


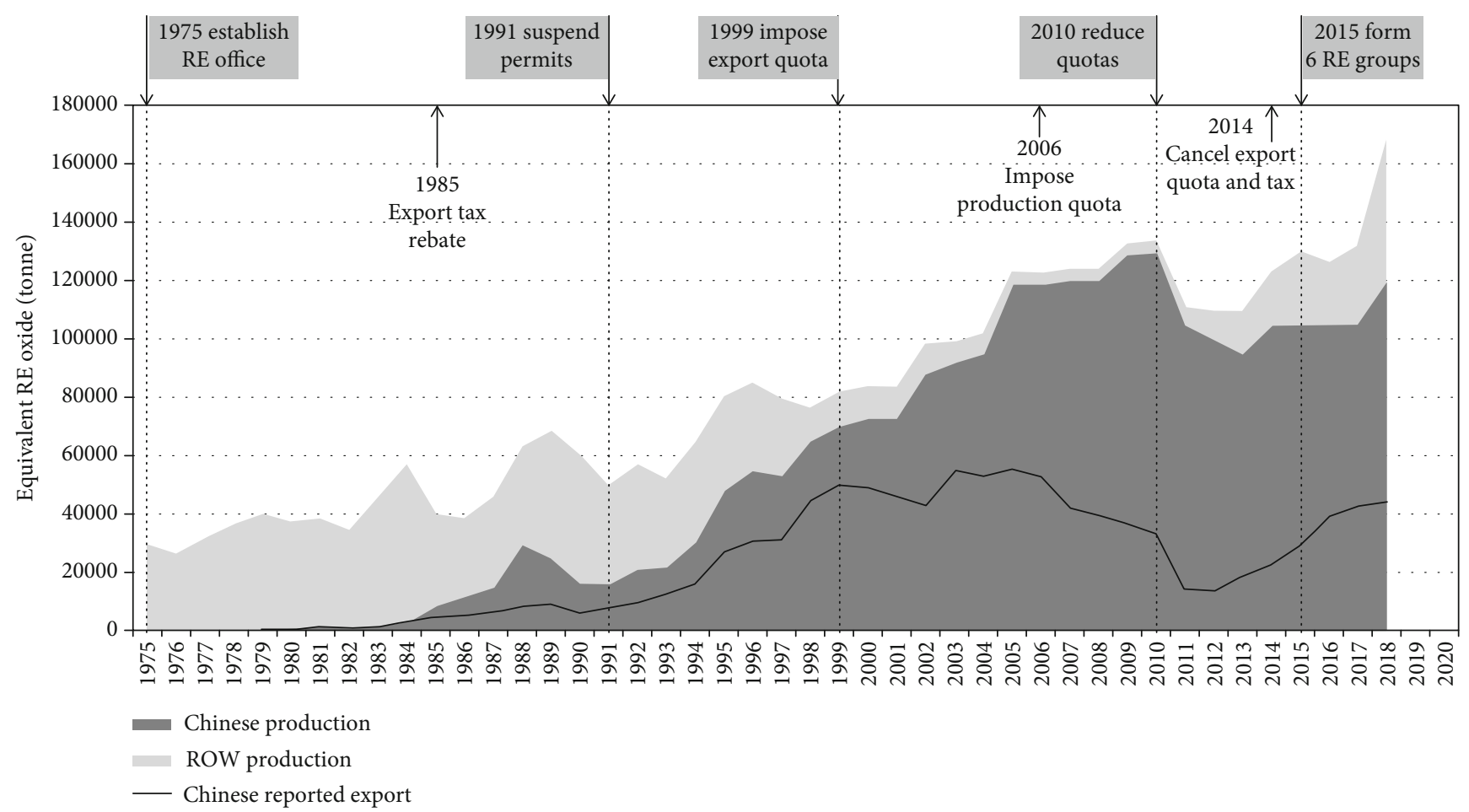

FIGURE 1: Chinese and rest-of-world mine production of rare earths [6]. This figure is reproduced from Shen et al. (2020) (under the Creative Commons Attribution License/public domain).

accomplished with aqueous electrolyte solution (ammonium sulfate $\left.\left(\left(\mathrm{NH}_{4}\right)_{2} \mathrm{SO}_{4}\right)\right)$. The ion exchange reaction between kaolinite and $\left(\mathrm{NH}_{4}\right)_{2} \mathrm{SO}_{4}$ can be chemically represented as [10]

$$
\begin{aligned}
& 2(\text { kaolin })^{3-} \mathrm{RE}^{3+}+3\left(\mathrm{NH}_{4}\right)_{2} \mathrm{SO}_{4} \\
& \quad \longrightarrow 2(\text { kaolin })^{3-}\left(\mathrm{NH}_{4+}\right)_{3}+\left(\mathrm{RE}^{3+}\right)_{2}\left(\mathrm{SO}_{4}^{2-}\right)_{3}
\end{aligned}
$$

Many scholars had made some contributions to in situ leach mining technology. Larson summarized the information of in situ leach mining in the United States [11]. Mudd tested the technique of in situ leach mining in Australia, and he conducted the research on the issues related to chemistry and the environment [12]. Taylor et al. argued that the process of ISL (in situ leach) had considerably less environmental impact than other conventional mining techniques [13]. Parker and Jupe indicated that the technique of energy recovery from HDR (Hot Dry Rock) should be applied to leaching mining investigations [14]. Al-Harahsheh and Kingman summarized the methods of leaching mining assisted by microwaves, in which the microwave technology had great potential to improve the extraction efficiency [15]. Xunzhong and Maonan made an introduction to the technical process of in situ leaching of ion-absorbed rare earth minerals, and they proved that this type of in situ leaching had many advantages [16]. Based on the principle of pollution control, Zhu et al. proposed six pollution control measures to serve as reference for mine design, pollution management, and research work [17]. Li et al. reviewed the development of techniques on the protection of resource and environment during the exploitation process and proposed an environmental engineering model for ionabsorbed rare earth mining [18]. In the cyclic impact times, with the increase of repeated action times of impact loads, Zhu et al. indicated that the deformation modulus and yield stress of granite decreased and yield strain increased [19]. Under cyclic impaction, Jin et al. established an evolution model of damage accumulation of rocks, which was like the S-shaped growth curve [20]. Yan et al. found the relationship between dynamic load properties and porosity based on the dynamic load test of weakly weathered granites, which could help to improve the permeability of granites [21, 22]. Therefore, the permeability of granite deposits was a critical issue affecting the mining cost and environmental protection.

It is of great significance to study the dynamic mechanical properties of granites in ion-adsorption rare earth deposits. Finding the relationship between the variation of porosity and dynamic loads should be the key point to improve the permeability of granites in ore deposits. Besides, establishing the connection between the quantified damage level and the porosity greatly made sense for leaching mining and environmental protection. However, the current research results lacked the research on the above issues, especially for ionadsorption rare earth ores under the condition of in situ leaching mining. In this paper, the split Hopkinson pressure bar (SHPB) test system was equipped to conduct the dynamic uniaxial loading test. And the longitudinal wave velocity of rock samples can be recorded by the ultrasonic wave detector, helping to reduce the dispersion of rock samples and to quantify the damage degree of granites under dynamic loading. The test results offered an opportunity to analyze the 
dynamic behavior and porosity properties of granites under SHPB test, which would effectively improve the permeability of granites in ion-adsorption rare earth deposits.

\section{Experimental Work}

2.1. Granite Specimen Preparation. This experiment used granites in northern areas of Sichuan province, China. The geology stratum was composed of the Bikou Group and the overlying Sinian and Paleozoic sedimentary rocks, and there were more Indochina granites in the Bikou Group. The granite was off-white medium-fine-grained feldspar granite, which was grayish-white, with medium-fine-to-fine granite structure and massive. The main mineral components were (1) quartz, other-shaped granular, content about 22.9\%; (2) plagioclase, self-shaped columnar, content $53.9 \%$; (3) potash feldspar, irregular plate shape, content 17.6\%; and (3) darkcolored minerals, mainly biotite, semi-self-flaky, polychromatic, content 5.6\%, with hornblende being rare. (4) The secondary minerals are mainly sphene and apatite, followed by zircon, sphene, and magnetite. The XRD diffraction spectrum of granite is shown in Figure 2.

According to Standard for test methods of engineering rock mass, 2013 (GB/T 50266-2013, China), the doublesided grinding machine was used for fine processing to ensure that the parallelism error was less than $0.05 \mathrm{~mm}$, and the error of the height and diameter of the specimen was not more than $0.3 \mathrm{~mm}$. There were two sizes of specimens in this experiment. One size was made for uniaxial loading test, with the diameter of $50 \mathrm{~mm}$ and the height of $100 \mathrm{~mm}$, and the other was for dynamic loading test, with the diameter of $50 \mathrm{~mm}$ and the height of $50 \mathrm{~mm}$.

2.2. Split Hopkinson Pressure Bar (SHPB) Test System. A conventional SHPB test system was employed to conduct high strain-rate compression tests on rock specimens. The SHPB system consisted of an air gun, a striker bar, a barrel, an incident bar, a transmitted bar, a stopper, two strain gauges, a strain amplifier, and a computer, which is shown in Figure 3. In this paper, bars of SHPB used in this experiment were $40 \mathrm{Cr}$ alloy steel. The density was $7.81 \mathrm{~g} / \mathrm{cm}^{3}$, the elastic wave velocity was $5410 \mathrm{~m} / \mathrm{s}$, and the diameter of the bars was $50 \mathrm{~mm}$. The lengths of the incident bar and the transmitted bar were $2 \mathrm{~m}$ and $1.5 \mathrm{~m}$, respectively. The system can achieve the dynamic loading from 0 to $500 \mathrm{MPa}$. The oscilloscope (DL850) was produced by Yokogawa Electric Co., Ltd. to monitor the strain changes of bars, which is shown in Figure 4.

In the equations below $[23,24]$, the following symbols were used in this paper: (1) incident wave $(I),(2)$ transmitted wave $(T)$, (3) reflected wave $(R)$, (4) rock specimen $(s)$, (5) density of bars $(\rho)$, (6) elastic modulus of bars $(E)$, (7) velocity of waves in bars $(c),(8)$ cross-sectional area of bars $(A),(9)$ cross-sectional area of specimens $\left(A_{s}\right)$, and (10) length of specimens $\left(l_{0}\right)$. If the specimen deformed uniformly, the strain rate $\dot{\varepsilon}_{s}$ was calculated as follows (Figure 5):

$$
\dot{\varepsilon}_{s}=\frac{d \varepsilon_{s}}{d t}=\frac{v_{1}(t)-v_{2}(t)}{l_{0}} .
$$

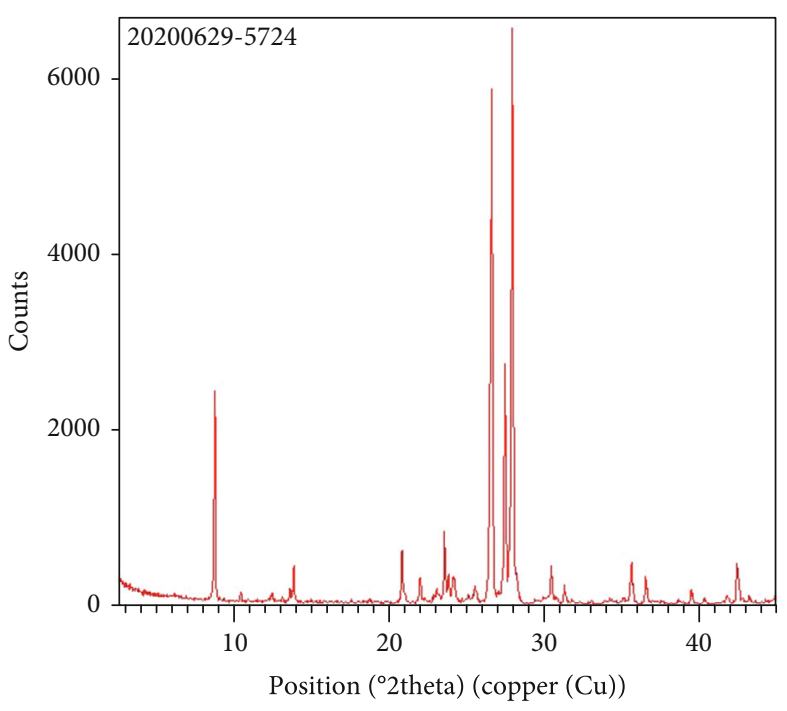

FIGURE 2: XRD diffraction spectrum of granite.

The velocity at interface $1\left(v_{1}\right)$ and interface $2\left(v_{1}\right)$ can be written as follows:

$$
v_{1}(t)=c\left(\varepsilon_{I}(t)-\varepsilon_{R}(t)\right), v_{2}(t)=c \varepsilon_{T}(t) .
$$

By substituting these interface velocities into Equation (2),

$$
\dot{\varepsilon}_{s}=\frac{c\left[\varepsilon_{I}(t)-\varepsilon_{R}(t)-\varepsilon_{T}(t)\right]}{l_{0}} .
$$

Stresses at the ends of the specimen were

$$
\begin{aligned}
\sigma_{1}(t) & =\frac{E A}{A_{s}}\left[\varepsilon_{I}(t)+\varepsilon_{R}(t)\right], \\
\sigma_{2}(t) & =\frac{E A}{A_{s}} \varepsilon_{T}(t) .
\end{aligned}
$$

If the specimen was in dynamic stress equilibrium,

$$
\varepsilon_{I}(t)+\varepsilon_{R}(t)=\varepsilon_{T}(t) .
$$

Then, the stress, strain rate, and strain were given by 。

$$
\begin{aligned}
\sigma_{s}(t) & =\frac{\sigma_{1}(t)+\sigma_{2}(t)}{2}=\frac{E A}{A_{s}}\left[\varepsilon_{I}(t)+\varepsilon_{R}(t)\right], \\
\dot{\varepsilon}_{s}(t) & =\frac{-2 c}{l_{0}} \varepsilon_{R}(t), \\
\varepsilon_{s} & =\frac{-2 c}{l_{0}} \int \varepsilon_{R}(t) d t .
\end{aligned}
$$

2.3. Ultrasonic Wave Detector. The detector named V-Meter MK IV was produced by the NDT Company. In this paper, the longitudinal P-wave was used as a measurement method. The P-wave velocity was calculated using the transmission travel time of an acoustic pulse along the axial direction of 


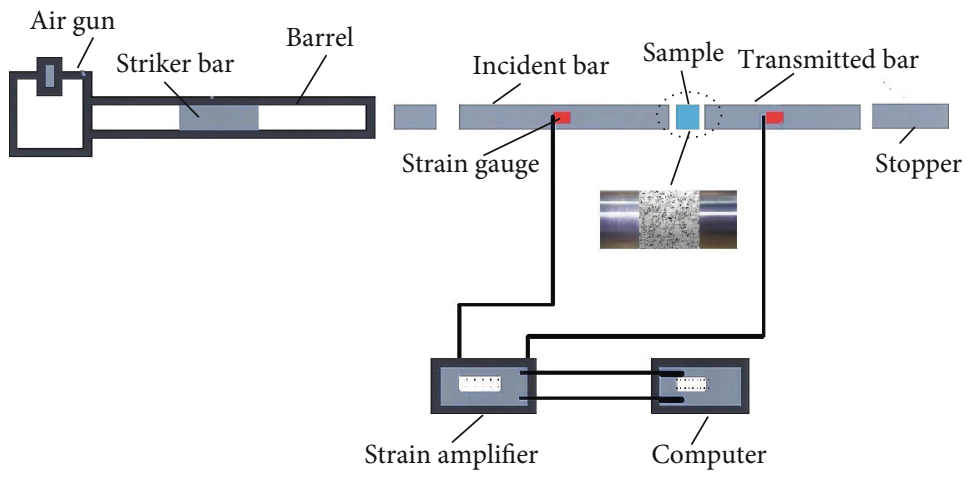

Figure 3: Schematic of the split Hopkinson pressure bar system.

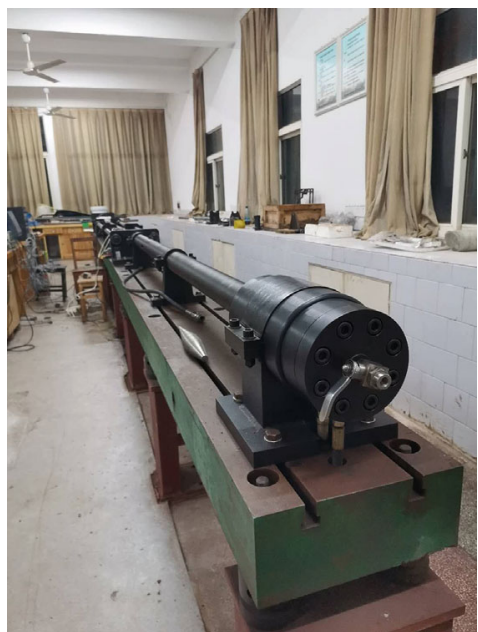

(a)

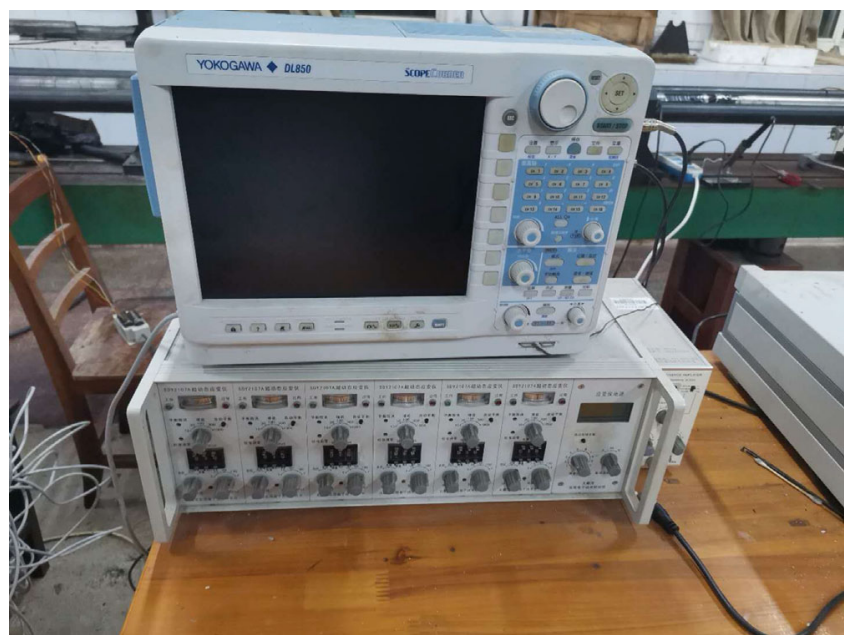

(b)

Figure 4: (a) SHPB test system and (b) the oscilloscope.

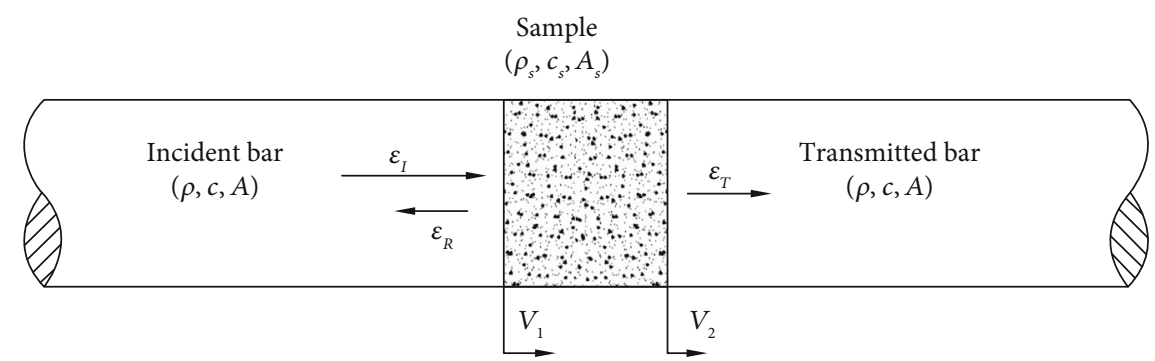

FIGURE 5: Symbols describing the parameters for the incident and transmitted bars and the specimen interface velocities [24].

the samples [25]. The experimental setup includes a waveform generator; two piezoelectric transducers, with a resonant frequency of $540 \mathrm{kHz}$; and a numerical oscilloscope board connected to a computer. A constant pressure by hand was applied to ensure tight contact between the rock specimen and the transducers. And Vaseline was used as the coupling agent. Checks were performed to ensure the sensitivity of the P-wave velocity measurement. Usually, two piezoelectric transducers were directly contacted for the error test, and the error was from 0 to $0.1 \mu \mathrm{s}$. In addition, the damage factor can be calculated as follows:

$$
D=1-\left(\frac{v_{1}}{v_{2}}\right)^{2}
$$

where $v_{1}$ is the ultrasonic wave velocity after rock damage and $v_{2}$ is the ultrasonic wave velocity before rock damage. The ultrasonic wave detector is shown in Figure 6. 


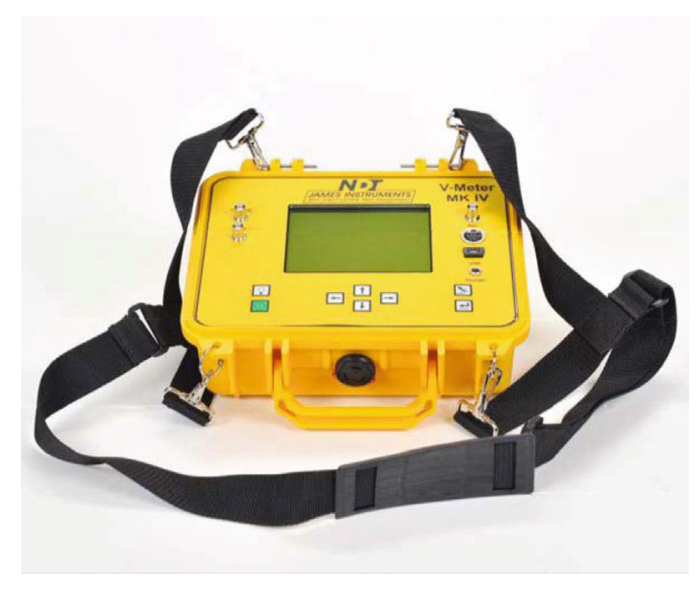

FiguRE 6: Ultrasonic wave detector.

2.4. Porosity Test Method and Device. The porosity of granites was measured by the saturation weighing method. The specific steps of this measurement method are as follows: (1) dry the specimen for $24 \mathrm{~h}$ at $105^{\circ} \mathrm{C}$; (2) place the specimen in a vacuum device filled with water and evacuate for $4 \mathrm{~h}$, with the vacuum pressure of $0.1 \mathrm{MPa}$; (3) put the specimen in water for $24 \mathrm{~h}$; and (4) weigh the saturated specimen. In order to minimize the error of weighting after the specimen was saturated, the electronic scale was calibrated with a standard weight of $500 \mathrm{~g}$ before each weighing. Finally, porosity test devices are shown in Figure 7.

\subsection{Experimental Process}

(1) Firstly, the main mineral components were analyzed, and the XRD diffraction spectrum of the granite was obtained. Secondly, some specimens with a diameter of $50 \mathrm{~mm}$ and a height of $100 \mathrm{~mm}$ were used for the conventional uniaxial static tests. Some basic mechanical properties were obtained after this process

(2) Based on the SHPB test system, extensive dynamic uniaxial compression tests on natural granites were conducted to find the dynamic characteristics of granites under different impact velocities. And granite specimens had a diameter of $50 \mathrm{~mm}$ and a height of $50 \mathrm{~mm}$. Then, multiple cyclic dynamic loading tests were conducted to find the threshold which causes the initial damage of granites under the impact of equal velocity

(3) Cyclic dynamic loading tests for granites were conducted. At the same time, P-wave velocities of granites were obtained by using an ultrasonic wave detector. Meanwhile, the porosity of granites was obtained by weighing saturated specimens. Before weighing, specimens need to be vacuumed and saturated for $4 \mathrm{~h}$ and were then soaked in water for $24 \mathrm{~h}$

\section{Results and Analysis}

3.1. Static Mechanical Properties of Granites. The static compression loading test was conducted on natural specimens of granites. And the MTS 815.03 test system was used to conduct the uniaxial compression test. The mechanical properties of granites are shown in Table 1. Moreover, axial and lateral stress-strain curves of granites and the failure type of granites are shown in Figure 8.

Based on the test results, the failure mode of granites was splitting failure, which is shown in Figure 8(b), because under the axial pressure, tensile stress was generated in the lateral direction. Then, the lateral tensile stress eventually exceeded the tensile limit of granites and caused failure. The main fracture was initiated near the center of specimens and spread along the vertical diameter. While the fracture ran through the entire height of the specimen, a secondary fracture emerged near the loading plate and formed some new microfractures.

In order to find out the cracking stress $\left(\sigma_{c i}\right)$ and the damaging stress $\left(\sigma_{c d}\right)$, the lateral strain response (LSR) method was used [26-28]. And the methodology can be summarized as follows, and the test results are shown in Figure 9.

(1) Determine the onset of unstable crack growth where total volumetric strain reversal occurs, which can find damaging stress $\left(\sigma_{c d}\right)$ (Figure 9(a))

(2) Determine the linear lateral strain reference line (Figure 9(b))

(3) Find the change ( $\triangle \mathrm{LSR}$ ) between the lateral line and the linear reference line in the lateral strain curve (Figure 9(b))

(4) Plot the axial stress versus change in the lateral strain $(\Delta \mathrm{LSR})$ (Figure 9(c))

(5) Determine the maximum change in the lateral strain difference and the associated axial stress, which can find the cracking stress $\left(\sigma_{c i}\right)$ (Figure 9(c))

3.2. Dynamic Mechanical Properties of Granites. Using the SHPB test system, there were two purposes which needed to be achieved. The first was to obtain the dynamic mechanical properties of granites under different loading velocities. The second was to find the threshold which caused the initial damage of granites. During the test, the compressive strain, associated with the transmitted wave, was recorded by strain gauges on the transmitted bar. These three elastic stress pulses in the incident and transmitted bars are recorded with the strain gauges and denoted as the incident strain $\varepsilon_{I}(t)$, reflected strain $\varepsilon_{R}(t)$, and transmitted strain $\varepsilon_{T}(t)$, as shown in Figure 10. The relationship between stresses and strains is shown in Figure 11. And dynamic mechanical properties of granites are illustrated in Table 2.

Many dynamic loading tests were conducted to analyze the dynamic mechanical properties of granites, and the results were as follows:

(1) In this paper, the test data with loading velocity between $9 \mathrm{~m} / \mathrm{s}$ and $13 \mathrm{~m} / \mathrm{s}$ were selected for processing and analysis. Under the same loading velocity, the waveform diagram corresponded to the stressstrain curve one by one. At the same time, within 


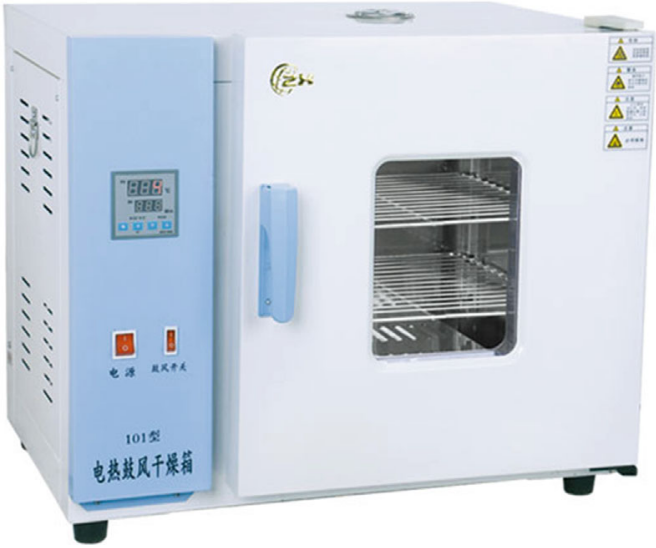

(a)

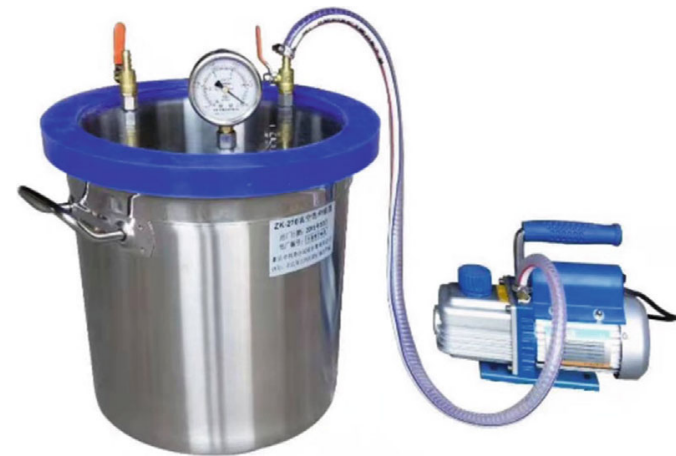

(b)

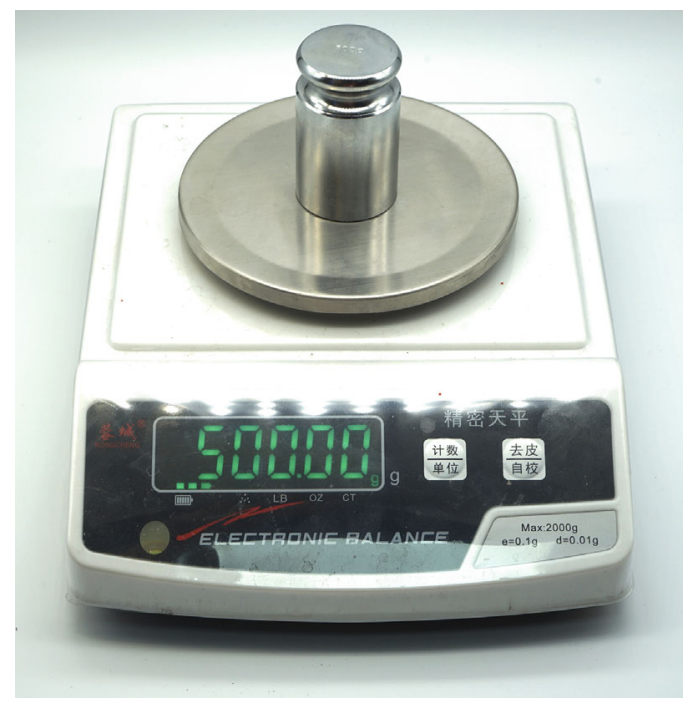

(c)

Figure 7: (a) Drying oven, (b) vacuum saturation device, and (c) electronic scale.

TABLE 1: Mechanical properties of granites.

\begin{tabular}{lccc}
\hline $\begin{array}{l}\text { Density } \\
\left(\mathrm{kg} / \mathrm{m}^{3}\right)\end{array}$ & $\begin{array}{c}\text { Elastic modulus } \\
(\mathrm{GPa})\end{array}$ & $\begin{array}{c}\text { Static strength } \\
(\mathrm{MPa})\end{array}$ & $\begin{array}{c}\text { Porosity } \\
(\%)\end{array}$ \\
\hline 2.59 & 15.73 & 89.12 & 0.91 \\
\hline
\end{tabular}

the range of loading velocities, the samples were destroyed under one dynamic load. It can be found from Figure 10 that the greater the loading velocity, the larger the amplitudes of the incident wave, the reflected wave, and the transmitted wave

(2) It can be seen from Figure 11 that the magnitude of dynamic strength and strain rate depended on the magnitude of the loading velocity. The greater the loading velocity, the larger the dynamic strength, the elastic modulus, and the strain rate were getting. At the same time, when the loading velocity increased, the higher the energy was released, and the number of granite fragments increased. From the perspective of the granite's failure form, the frac- ture surface of the granite was mostly parallel to the loading direction, the specimen mainly underwent the splitting failure, and there were multiple splitting cracks that penetrated the rock

Based on a large number of test results, when the loading velocity was between $8 \mathrm{~m} / \mathrm{s}$ and $9 \mathrm{~m} / \mathrm{s}$, the rock needed to be repeatedly loaded at the same rate once or twice before failure. In addition, when the loading velocity was between $7 \mathrm{~m} / \mathrm{s}$ and $8 \mathrm{~m} / \mathrm{s}$, the granite specimens needed to undergo 2 to 4 dynamic loading tests before failure. Moreover, when the loading velocity was between $6 \mathrm{~m} / \mathrm{s}$ and $7 \mathrm{~m} / \mathrm{s}$, the granite needed to be subjected to 4 to 6 times of loading tests before failure. However, when the loading velocity was lower than $5.8 \mathrm{~m} / \mathrm{s}$, after more than 30 cycles of loading test, the specimens cannot be damaged or even destroyed. The cyclic dynamic loading test results are shown in Table 3.

Based on the above analysis, there was indeed a stress threshold for granite failure at the lowest dynamic loading velocity. Obviously, the lowest velocity was $9.0 \mathrm{~m} / \mathrm{s}$, and the stress threshold for failure was $60.49 \mathrm{MPa}$. However, the threshold for cracking damage under cyclic dynamic loading 


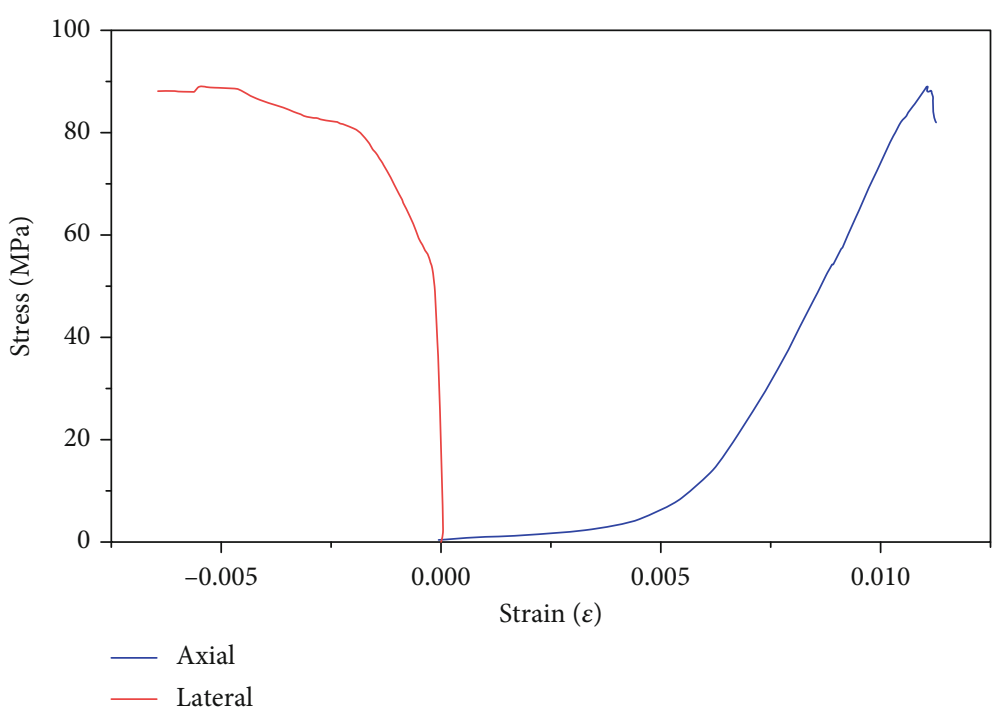

(a)

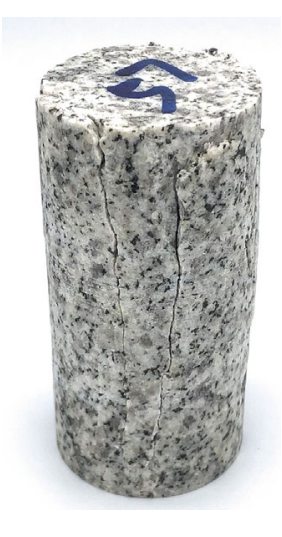

(b)

Figure 8: (a) The uniaxial stress-strain curves of granites and (b) the failure type of granites.

needs more analysis. Liang et al. indicated that there was no obvious correlation between the ratio of initiation stress and peak strength and strain rate in rock specimens [29]. Based on Liang et al.'s theory, the following equations can be obtained to predict the threshold for damage under dynamic loading:

$$
\begin{gathered}
\frac{\sigma_{c i}^{d}}{\sigma_{c}^{d}}=\alpha \frac{\sigma_{c i}}{\sigma_{c}}, \\
\frac{\sigma_{c d}^{d}}{\sigma_{c}^{d}}=\beta \frac{\sigma_{c d}}{\sigma_{c}},
\end{gathered}
$$

where $\sigma_{c i}^{d}, \sigma_{c d}^{d}$, and $\sigma_{c}^{d}$ are the cracking stress, damage stress, and ultimate strength under dynamic loading, respectively, and $\sigma_{c i}, \sigma_{c d}$, and $\sigma_{c}$ are the cracking stress, damage stress, and ultimate strength under static loading, respectively. $\alpha$ and $\beta$ are related coefficients.

Due to the uncertainty of the dynamic ultimate strength under different strain rates, this article assumed that the dynamic ultimate strength was equal to the static ultimate strength $\left(\sigma_{c}^{d}=\sigma_{c}\right)$. Thus, the dynamic cracking stress $\sigma_{c i}^{d}$ was $39.62 \mathrm{MPa}$, and the dynamic damage stress $\sigma_{c d}^{d}$ was $55 \mathrm{MPa}$. Based on Table 3, when the dynamic ultimate strength of the specimen was close to the dynamic damage stress, the sample needed to be impacted more times to failure. Therefore, under constant-cyclic dynamic loading, the lowest velocity was $5.8 \mathrm{~m} / \mathrm{s}$, and the stress threshold for failure was $55.1 \mathrm{MPa}$, which was very close to the damage stress under static loading.

3.3. Analysis of Granite Porosity and Damage Degree under Cyclic Loading. As mentioned in the previous section, when the loading velocity was greater than $9 \mathrm{~m} / \mathrm{s}$, the granite would fail by one time of the loading test. When the loading velocity was less than $5.8 \mathrm{~m} / \mathrm{s}$, no obvious damage and destruction had occurred in the sample after more than 30 times of the loading test. Therefore, this paper mainly worked on the damage characteristics and porosity changes of granites under the loading velocities from $5.8 \mathrm{~m} / \mathrm{s}$ to $8.4 \mathrm{~m} / \mathrm{s}$. The following figure shows the change of wave velocities of granites under cyclic dynamic loading.

In Figure 12, at a loading rate of $8.4 \mathrm{~m} / \mathrm{s}$, the ultrasonic wave velocity of D7 decreased faster, and the increment of the damage factor was also higher. And a significant longitudinal penetrating fissure appeared on the surface of the sample. This showed that the damage level of the sample was very serious, and it was close to the critical condition of failure. At a loading velocity of $7.2 \mathrm{~m} / \mathrm{s}$, the ultrasonic wave velocity of D10 gradually decreased, and the magnitude of the decrease gradually increased. At a loading velocity of $5.8 \mathrm{~m} / \mathrm{s}$, the wave velocity of D40 reduced slowly, which reduced fast in the last three impacts. Generally speaking, the greater the loading velocity, the greater the damage of the sample would be. But when the loading velocity was below a certain threshold, the sample would not be damaged.

In Figure 13(a), at a loading velocity of $8.4 \mathrm{~m} / \mathrm{s}$, the porosity of D7 increased rapidly from $0.94 \%$ to $1.41 \%$ after the single loading. Under the loading velocity of $5.8 \mathrm{~m} / \mathrm{s}$, after 12 cyclic loading tests, the porosity of the sample gradually increased from $0.98 \%$ to $1.44 \%$, and the growth rate gradually increased with the increase of the number of cycles, which can be seen as an exponential growth.

To describe the relationship between the damage factor and the porosity, Figure 13(b) was made to analyze this phenomenon. Through linear fitting, to some extent, there was a linear relationship between the damage factor and the porosity. That is to say, under the loading velocity from $5.8 \mathrm{~m} / \mathrm{s}$ to $8.4 \mathrm{~m} / \mathrm{s}$, the change of porosity can be predicted by the damage factor. Because of the development of a microfissure in rock specimens, the porosity had increased gradually. And the damage factor was a quantitative indicator that can well reflect the development of the microfissure in 


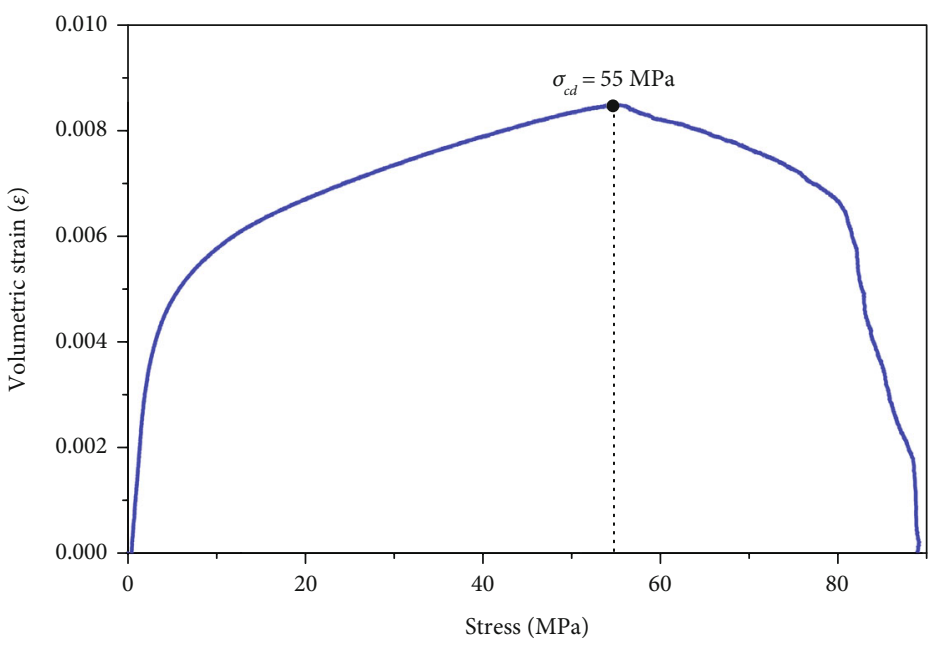

$-\Delta \mathrm{LSR}$

(a)

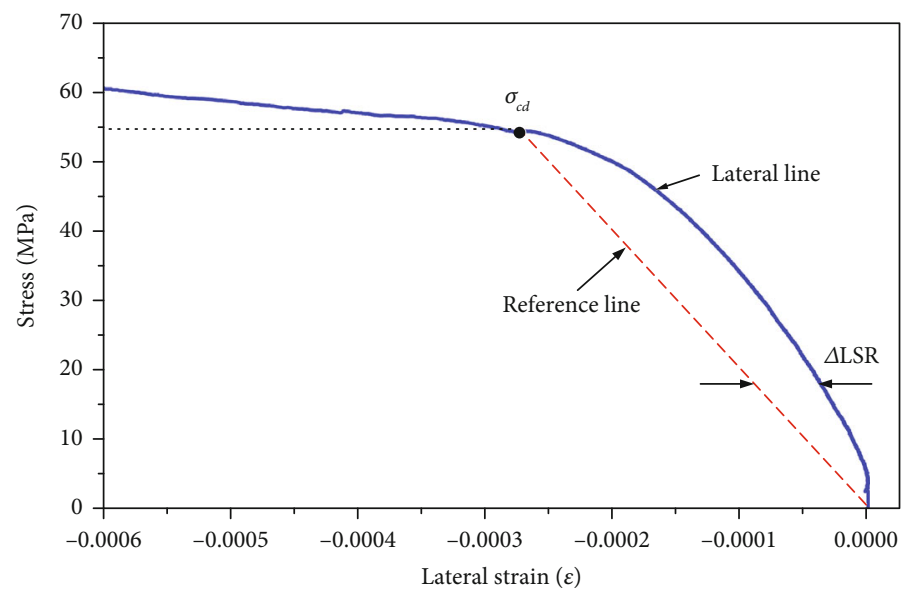

$-\Delta \mathrm{LSR}$

(b)

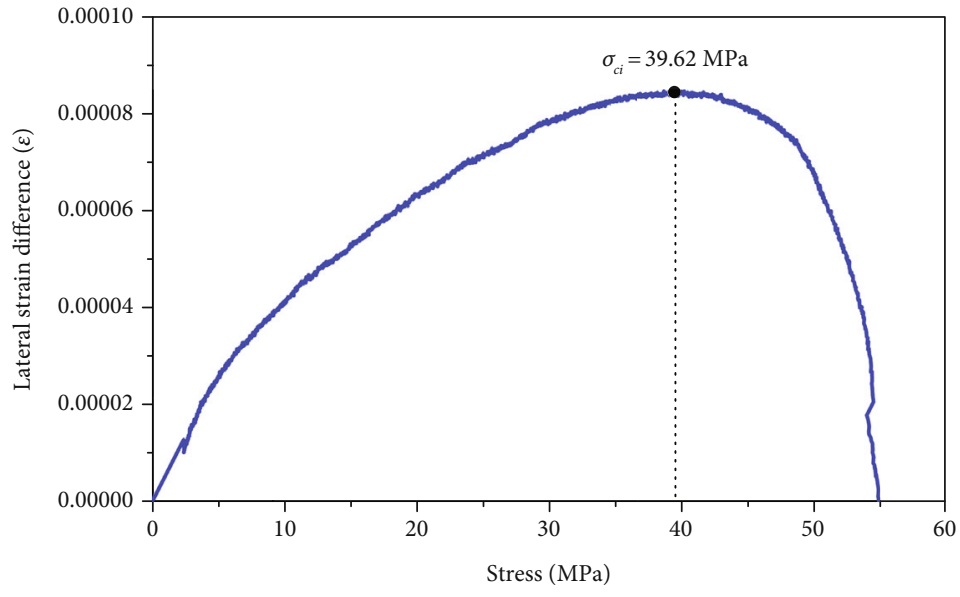

(c)

FIGURE 9: Example of the methodology used to establish the cracking stress $\left(\sigma_{c i}\right)$ using the lateral strain response (LSR). 


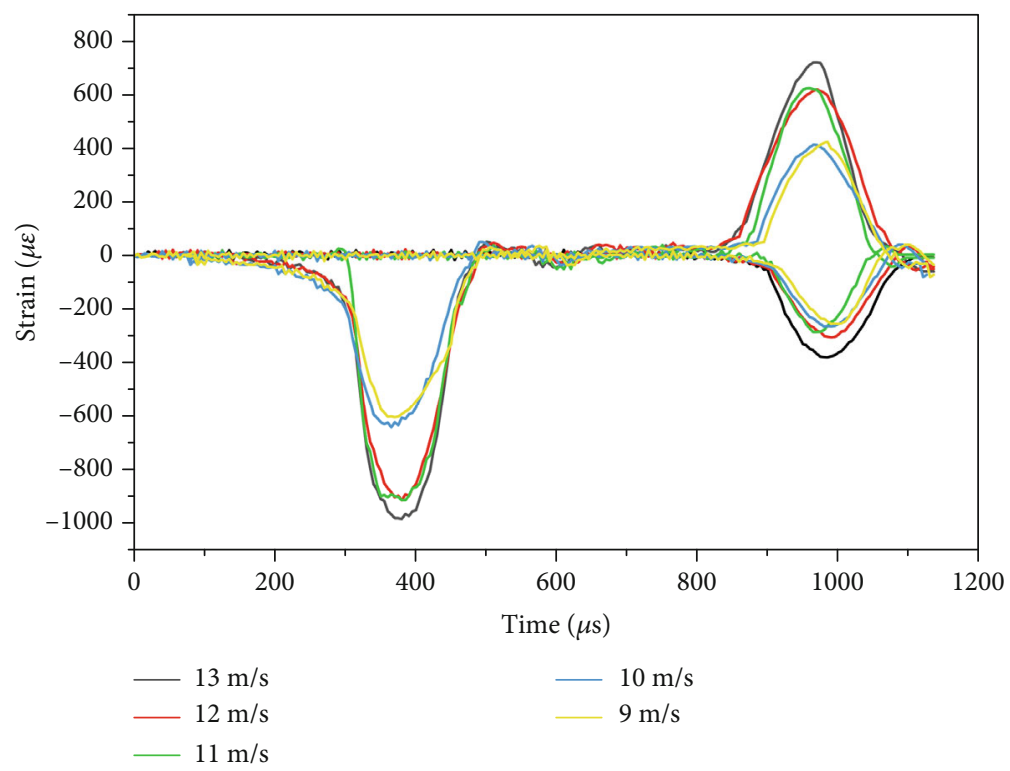

FIGURE 10: Some examples of incident, reflected, and transmitted strain signals under different loading velocities.

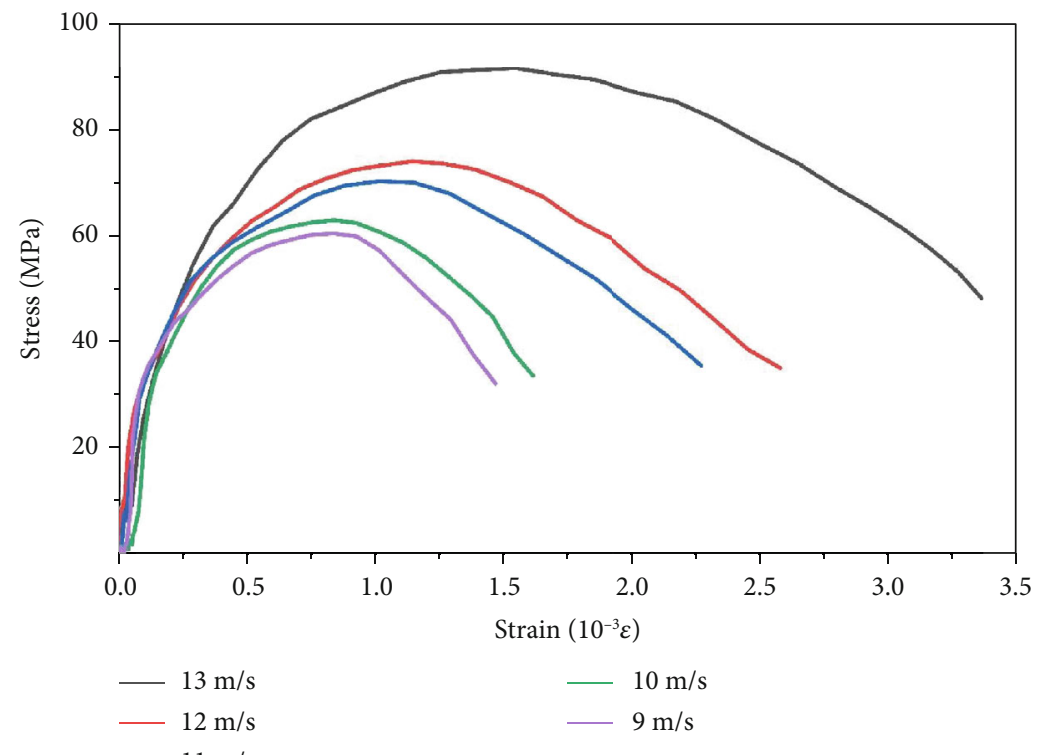

(a)
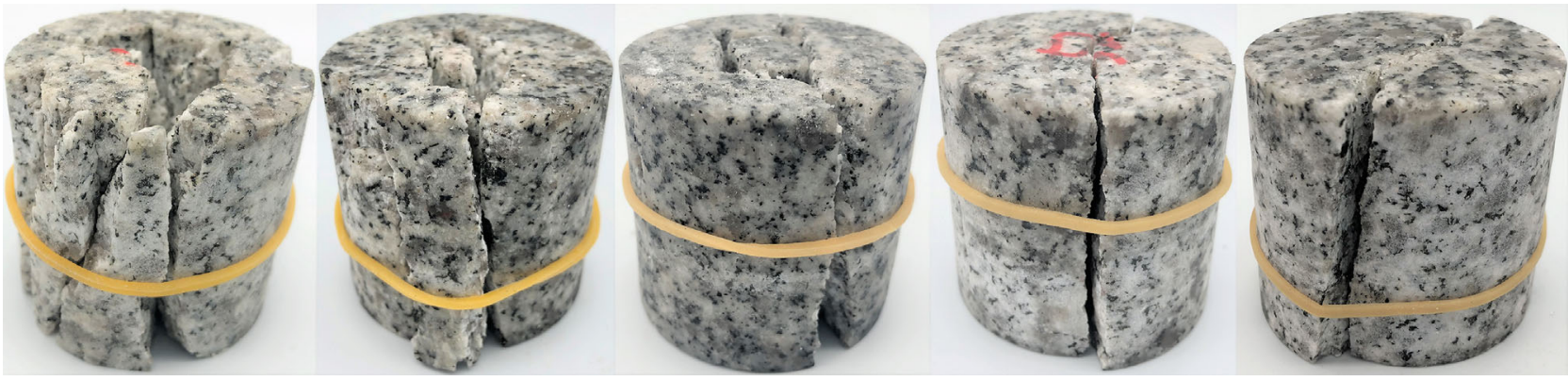

(b)

Figure 11: (a) Stress and strain change of granites under dynamic loading and (b) the failure types of granites with the impact velocity of $13 \mathrm{~m} / \mathrm{s}, 12 \mathrm{~m} / \mathrm{s}, 11 \mathrm{~m} / \mathrm{s}, 10 \mathrm{~m} / \mathrm{s}$, and $9 \mathrm{~m} / \mathrm{s}$, respectively. 
TABLE 2: Dynamic mechanical properties of granites.

\begin{tabular}{lcccccc}
\hline $\begin{array}{l}\text { Specimen } \\
\text { number }\end{array}$ & $\begin{array}{c}\text { Length to } \\
\text { diameter ratio }\end{array}$ & Initial wave velocity $(\mathrm{m} / \mathrm{s})$ & Striker velocity $(\mathrm{m} / \mathrm{s})$ & Strength (MPa) & $\begin{array}{c}\text { Strain rate }\left(\mathrm{s}^{-1}\right) \\
\begin{array}{c}\text { Number of } \\
\text { broken rocks }\end{array}\end{array}$ \\
\hline D33 & 1.021 & 3597 & 12.8 & 91.59 & 74.99 & 10 \\
D32 & 1.034 & 3543 & 11.7 & 74.02 & 70.43 & 6 \\
D57 & 1.016 & 3623 & 10.6 & 71.63 & 64.19 & 4 \\
D52 & 1.025 & 3649 & 9.6 & 62.99 & 18.86 \\
D23 & 1.031 & 3672 & 9.0 & 60.49 & 18.86 & 2 \\
\hline
\end{tabular}

TABLE 3: Constant-velocity cyclic dynamic loading test.

\begin{tabular}{lcccc}
\hline Specimen number & Ultrasonic wave velocity in saturation $(\mathrm{m} / \mathrm{s})$ & Average loading velocity $(\mathrm{m} / \mathrm{s})$ & Loading times & Ultimate strength $(\mathrm{MPa})$ \\
\hline D7 & 4524 & 8.4 & 2 & 58.8 \\
D10 & 4944 & 7.2 & 4 & 57.4 \\
D43 & 4665 & 6.9 & 5 & 56.9 \\
D40 & 4978 & 5.8 & 7 & 55.5 \\
D35 & 4653 & 6.3 & 30 & 56.1 \\
D50 & 4841 & 5.5 & & 55.1 \\
\hline
\end{tabular}

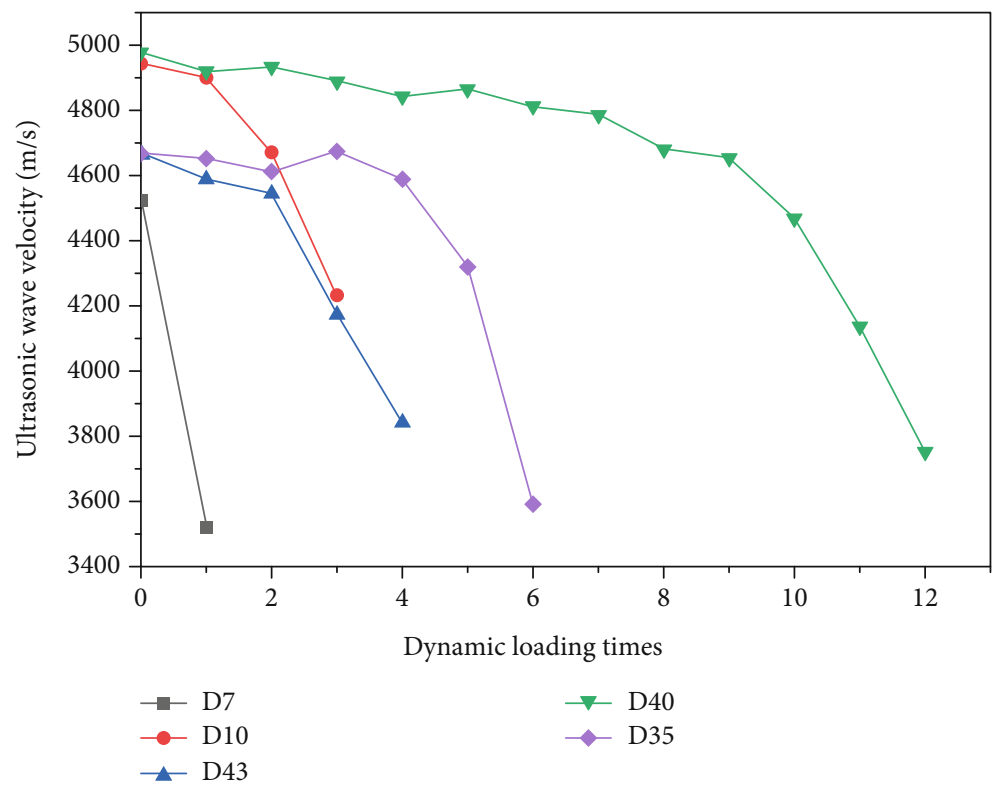

FIGURE 12: Relationship between the dynamic loading times and the ultrasonic wave velocity.

the rock. Therefore, in engineering practice, the porosity of rocks can be measured indirectly by the ultrasonic wave detector.

\section{Conclusion}

This paper presented the dynamic mechanical properties of granites based on the SHPB test system and the ultrasonic wave detector. The uniaxial dynamic mechanical properties with different loading velocities and the relationship between the dynamic mechanical properties and the porosity were analyzed as follows:

(1) Based on many tests, the failure mode of granites under static uniaxial compression load was very similar to its failure mode under dynamic uniaxial compression load. The fracture surface of the granite was mostly parallel to the loading direction, and the specimen mainly underwent the splitting failure. Moreover, according to test results, when the dynamic loading velocity was higher than $9 \mathrm{~m} / \mathrm{s}$, 


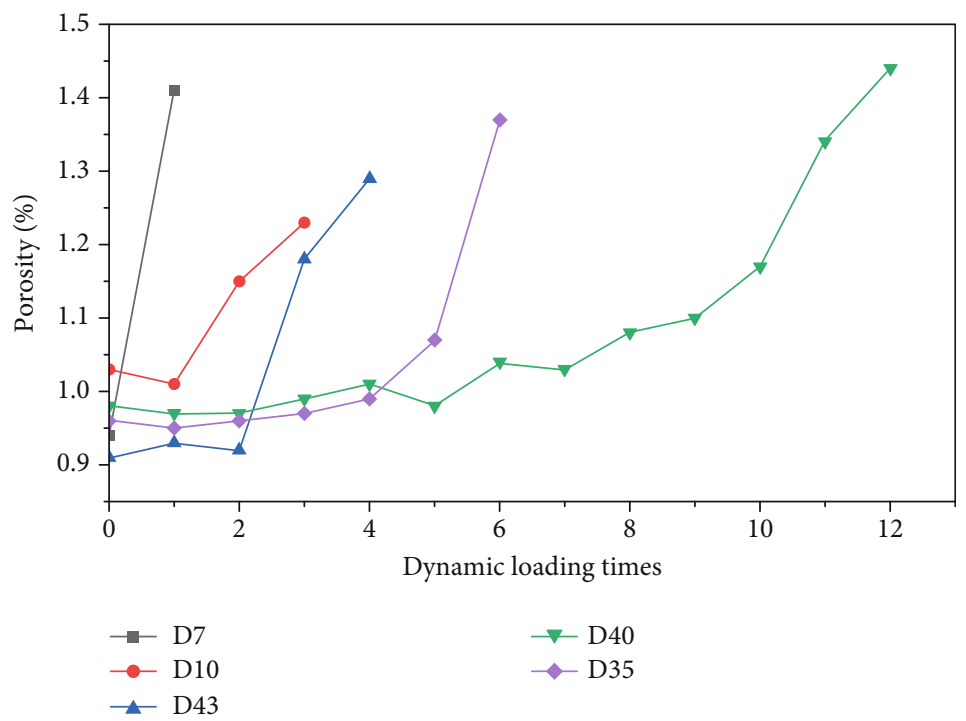

(a)

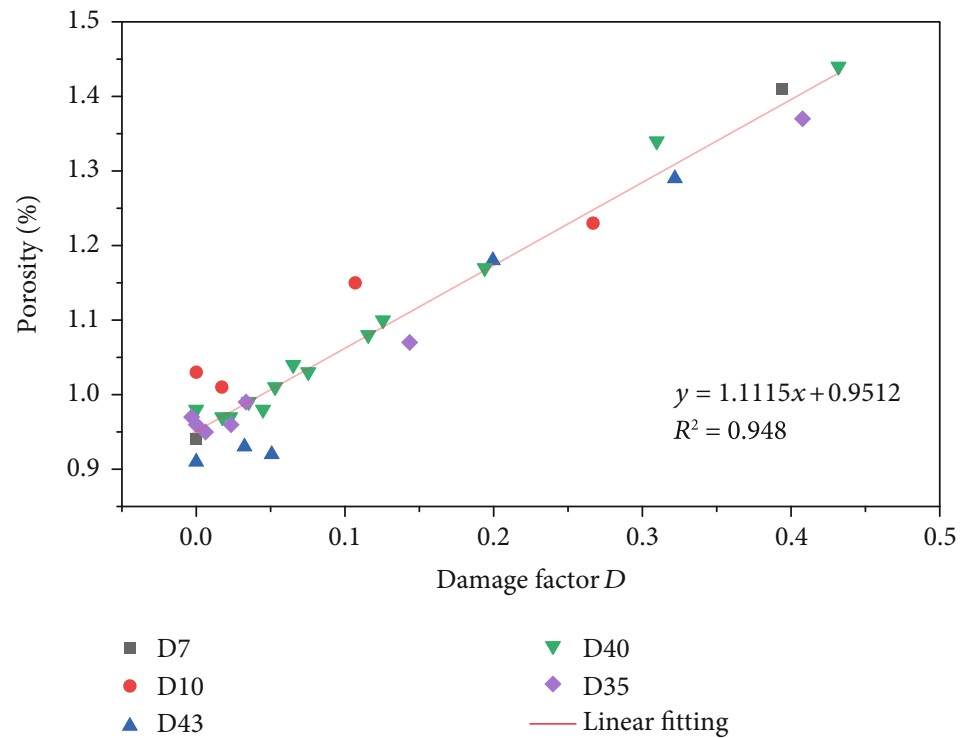

(b)

FIGURE 13: (a) Relationship between dynamic loading times and the porosity under different loading velocities and (b) relationship between the damage factor and the porosity.

granite specimens failed under one impact load. And when the dynamic loading velocities were from $5.8 \mathrm{~m} / \mathrm{s}$ to $8.4 \mathrm{~m} / \mathrm{s}$, granites had varying degrees of damage instead of failure

(2) Based on the test results, the minimum dynamic loading velocity causing granite failure was $9 \mathrm{~m} / \mathrm{s}$, in which the dynamic strength was $60.49 \mathrm{MPa}$. Moreover, under the cyclic dynamic loading, the minimum dynamic loading velocity causing granite failure was $5.8 \mathrm{~m} / \mathrm{s}$, in which the dynamic strength was $55.5 \mathrm{MPa}$. Based on Liang et al.'s theory, under the cyclic dynamic loading, when the dynamic strength was close to the static damage stress, granites needed to undergo more cyclic loads before failure occurred. When the dynamic strength of granites was very close to the static damage stress, it was almost impossible to cause any damage or failure for granites after 30 dynamic loads. Therefore, according to test results, static damage stress can be used to predict the dynamic threshold of initial damage under cyclic dynamic loading

(3) The changes of the porosity depended on the loading velocity and the number of dynamic loading. At the loading velocity of $8.4 \mathrm{~m} / \mathrm{s}$, the porosity grew fast, but the granite specimen was prone to failure; therefore, it was hard to control the change of the porosity under this velocity. At the loading velocity of $5.8 \mathrm{~m} / \mathrm{s}$, the porosity grew slowly. And it may take more time to control the porosity. Therefore, when the loading velocity was between $5.8 \mathrm{~m} / \mathrm{s}$ and $8.4 \mathrm{~m} / \mathrm{s}$, it can 
effectively control the porosity of granites. Moreover, this paper found the linear relationship between the change of the porosity and the damage factor, which would help to quantify and control the porosity changes in engineering practice

\section{Data Availability}

The data used to support the findings of this study are available from the corresponding author upon request.

\section{Conflicts of Interest}

The authors declare that they have no conflicts of interest.

\section{Acknowledgments}

The authors are grateful for the financial support from Sichuan University.

\section{References}

[1] C. Preinfalk and G. Morteani, "The industrial applications of rare earth elements," in in Lanthanides, tantalum and niobium, pp. 359-370, Springer, 1989.

[2] J. H. L. Voncken, The Rare Earth Elements: An Introduction, Springer, 2016.

[3] Anonymous, On Promoting Sustainable and Healthy Development of Rare Earth Industry. State Council of the People's Republic of China, State Council of the People's Republic of China, 2011.

[4] S. Massari and M. Ruberti, "Rare earth elements as critical raw materials: focus on international markets and future strategies," Resources Policy, vol. 38, no. 1, pp. 36-43, 2013.

[5] G. Gunn, Critical Metals Handbook, John Wiley \& Sons, 2014.

[6] Y. Shen, R. Moomy, and R. G. Eggert, "China’s public policies toward rare earths, 1975-2018," Mineral Economics, vol. 33, no. 1-2, pp. 127-151, 2020.

[7] X. J. Yang, A. Lin, X.-L. Li, Y. Wu, W. Zhou, and Z. Chen, "China's ion-adsorption rare earth resources, mining consequences and preservation," Environmental Development, vol. 8, pp. 131-136, 2013.

[8] W. Su, Economic and Policy Analysis of China's Rare Earth Industry, China Financial and Economic Publishing House, Beijing, 2009.

[9] J. Voncken, The Rare Earth Elements - An Introduction, Springer International Publishing, 2016.

[10] X. Tang and M. Li, "In-situ leach mining fo ion-absorbed rare earth mining," Mining research and development, vol. 17, pp. 1-4, 1997.

[11] W. C. Larson, Uranium in situ leach mining in the United States. Information circular, Department of the Interior, Bureau of Mines, 1978.

[12] G. Mudd, "Critical review of acid in situ leach uranium mining: 1. USA and Australia," Environmental Geology, vol. 41, no. 3-4, pp. 390-403, 2001.

[13] G. Taylor, V. Farrington, P. Woods, R. Ring, and R. Molloy, "Review of environmental impacts of the acid in-situ leach uranium mining process," CSIRO Land and Water Client Report, CSIRO Clayton, Victoria, 2004.
[14] R. H. Parker and A. Jupe, "In situ leach mining and hot dry rock (HDR) geothermal energy technology," Minerals Engineering, vol. 10, no. 3, pp. 301-308, 1997.

[15] M. Al-Harahsheh and S. W. Kingman, "Microwave-assisted leaching-a review," Hydrometallurgy, vol. 73, no. 3-4, pp. 189-203, 2004.

[16] T. Xunzhong and L. Maonan, "In-situ leach mining of ionabsorbed rare-earth mineral," Mining research and development, vol. 2, 1997.

[17] Y. Zhu, L. Zhou, and Q. Li, "Water pollution prevention method for in-situ leach mining of ion-absorbed rare-earth mineral," Nonferrous Metals (Mineral Processing Section), vol. 6, pp. 46-49, 2011.

[18] Y.-x. Li, L. Zhang, and X.-m. Zhou, "Resource and environment protected exploitation model for ion-type rare earth deposit in southern of China," Chinese Rare Earths, vol. 31, no. 2, pp. 80-85, 2010.

[19] J. J. Zhu, X. B. Li, F. Q. Gong, and S. M. Wang, "Dynamic characteristics and damage model for rock under uniaxial cyclic impact compressive loads," Chinese Journal of Geotechnical Engineering, vol. 35, no. 3, pp. 531-539, 2013.

[20] J. Jin, X. Li, C. Qiu et al., "Evolution model for damage accumulation of rock under cyclic impact loadings and effect of static loads on damage evolution," Chinese Journal of Rock Mechanics and Engineering, vol. 33, no. 8, pp. 1662-1671, 2014.

[21] L. Yan, L. Liu, S. Zhang, D. Lan, and J. Liu, “Testing of Weakly Weathered Granites of Different Porosities Using a Split Hopkinson Pressure Bar Technique," Advances in Civil Engineering, vol. 2018, Article ID 5267610, 11 pages, 2018.

[22] L. Yan, W. Yi, L. Liu, J. Liu, and S. Zhang, "Blasting-Induced Permeability Enhancement of Ore Deposits Associated with Low-Permeability Weakly Weathered Granites Based on the Split Hopkinson Pressure Bar," Geofluids, vol. 2018, Article ID 4267878, 14 pages, 2018.

[23] M. A. Kaiser, Advancements in the Split Hopkinson Bar Test, Virginia Tech, 1998.

[24] S. Demirdag, K. Tufekci, R. Kayacan, H. Yavuz, and R. Altindag, "Dynamic mechanical behavior of some carbonate rocks," International Journal of Rock Mechanics and Mining Sciences, vol. 47, no. 2, pp. 307-312, 2010.

[25] M. Takarli, W. Prince, and R. Siddique, "Damage in granite under heating/cooling cycles and water freeze-thaw condition," International Journal of Rock Mechanics and Mining Sciences, vol. 45, no. 7, pp. 1164-1175, 2008.

[26] T. Stacey, "A simple extension strain criterion for fracture of brittle rock," in International Journal of Rock Mechanics and Mining Sciences \& Geomechanics Abstracts, pp. 469-474, Elsevier, 1981.

[27] M. S. Diederichs, “The 2003 Canadian Geotechnical Colloquium: Mechanistic interpretation and practical application of damage and spalling prediction criteria for deep tunnelling," Canadian Geotechnical Journal, vol. 44, no. 9, pp. 1082-1116, 2007.

[28] M. Nicksiar and C. D. Martin, "Evaluation of methods for determining crack initiation in compression tests on lowporosity rocks," Rock Mechanics and Rock Engineering, vol. 45, no. 4, pp. 607-617, 2012.

[29] C. Y. Liang, X. Li, S. X. Wang, S. D. Li, J. M. He, and C. F. Ma, "Experimental investigations on rate-dependent stress-strain characteristics and energy mechanism of rock under uniaixal compression," Chinese Journal of Rock Mechanics and Engineering, vol. 31, no. 9, pp. 1830-1838, 2012. 